\title{
Outcomes and management approaches of resuscitative endovascular balloon occlusion of the aorta based on the income of countries
}

Ramiro Manzano-Nunez ${ }^{1,2,3,4^{*}}$, David McGreevy ${ }^{3}$, Claudia P. Orlas ${ }^{1}$, Alberto F. García ${ }^{5}$, Tal M. Hörer ${ }^{3}$, Joseph DuBose ${ }^{6}$, Carlos A. Ordoñez ${ }^{5}$ and on behalf of the AAST-AORTA Investigators and the ABOTrauma Registry Group

\begin{abstract}
Background: Resuscitative endovascular balloon occlusion of the aorta (REBOA) could provide a survival benefit to severely injured patients as it may improve their initial ability to survive the hemorrhagic shock. Although the evidence supporting the use of REBOA is not conclusive, its use has expanded worldwide. We aim to compare the management approaches and clinical outcomes of trauma patients treated with REBOA according to the countries' income based on the World Bank Country and Lending Groups.

Methods: We used data from the AORTA (USA) and the ABOTrauma (multinational) registries. Patients were stratified into two groups: (1) high-income countries (HICS) and (2) low-to-middle income countries (LMICs). Propensity score matching extracted 1:1 matched pairs of subjects who were from an LMIC or a HIC based on age, gender, the presence of pupillary response on admission, impeding hypotension (SBP $\leq 80)$, trauma mechanism, ISS, the necessity of CPR on arrival, the location of REBOA insertion (emergency room or operating room) and the amount of PRBCs transfused in the first $24 \mathrm{~h}$. Logistic regression (LR) was used to examine the association of LMICs and mortality.

Results: A total of 817 trauma patients from 14 countries were included. Blind percutaneous approach and surgical cutdown were the preferred means of femoral cannulation in HICS and LIMCs, respectively. Patients from LMICs had a significantly higher occurrence of MODS and respiratory failure. LR showed no differences in mortality for LMICs when compared to HICs; neither in the non-matched cohort ( $\mathrm{OR}=0.63 ; 95 \% \mathrm{Cl}: 0.36-1.09 ; p=0.1)$ nor in the matched cohort $(\mathrm{OR}=1.45 ; 95 \% \mathrm{Cl}: 0.63-3,33 ; p=0.3)$.
\end{abstract}

\footnotetext{
* Correspondence: ramiro.manzano@fvl.org.co

${ }^{1}$ Clinical Research Center, Fundacion Valle del Lili, Cali, Colombia

¿Universidad del Rosario, Escuela de Medicina y Ciencias de la Salud, Bogotá, Colombia

Full list of author information is available at the end of the article
}

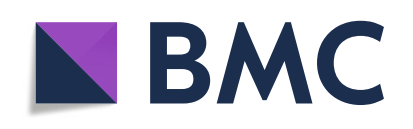

( ) The Author(s). 2020 Open Access This article is licensed under a Creative Commons Attribution 4.0 International License, which permits use, sharing, adaptation, distribution and reproduction in any medium or format, as long as you give appropriate credit to the original author(s) and the source, provide a link to the Creative Commons licence, and indicate if changes were made. The images or other third party material in this article are included in the article's Creative Commons licence, unless indicated otherwise in a credit line to the material. If material is not included in the article's Creative Commons licence and your intended use is not permitted by statutory regulation or exceeds the permitted use, you will need to obtain permission directly from the copyright holder. To view a copy of this licence, visit http://creativecommons.org/licenses/by/4.0/. The Creative Commons Public Domain Dedication waiver (http://creativecommons.org/publicdomain/zero/1.0/) applies to the data made available in this article, unless otherwise stated in a credit line to the data. 


\begin{abstract}
(Continued from previous page)
Conclusion: There is considerable variation in the management practices of REBOA and the outcomes associated with this intervention between HICs and LMICs. Although we found significant differences in multiorgan and respiratory failure rates, there were no differences in the risk-adjusted odds of mortality between the groups analyzed. Trauma surgeons practicing REBOA around the world should joint efforts to standardize the practice of this endovascular technology worldwide.
\end{abstract}

Keywords: REBOA, Income of countries, Trauma

\section{Introduction}

Resuscitative endovascular balloon occlusion of the aorta (REBOA) is becoming an appealing alternative in the resuscitation of exsanguinating patients with noncompressible torso hemorrhage ( $\mathrm{NCTH})$ [1]. Its use, as a tool within the broad concept of endovascular resuscitation and trauma management [2], has expanded worldwide [3-5], and data on trauma patients treated with REBOA from different countries in the world have been collected in different registries [6, 7]. Furthermore, the field of endovascular hemorrhage control has experienced significant growth in the past years, and literature has emerged that offers contradictory findings of its safety and effectiveness [1, 8-10].

Although REBOA is being used worldwide, there is evident variation in working conditions, workforce training, available health care systems, and economic resources across different countries. These factors may have a significant impact on the care, and surgical outcome of REBOA resuscitated patients. In order to address the variations between regions and countries in relation to their income, we aim to compare the management approaches and clinical outcomes of trauma patients resuscitated with REBOA according to the countries' income based on the World Bank Country and Lending Groups.

\section{Methods}

The data presented in this observational study represents a cohort of trauma patients resuscitated with REBOA worldwide.

\section{Data source}

For this study, we used data from the AORTA and the ABOTrauma registries. These registries were launched to collect patient and outcome data from trauma patients treated with REBOA. Details of each registry (AORTA, ABOTrauma) have been outlined in previous publications $[6,7,11,12]$.

In brief, the AORTA registry is an initiative of the AAST Multicenter Trials Committee and collects data of adult trauma patients (age 18 or older) undergoing aortic occlusion (either by aortic cross-clamping or by REBOA) in the acute phases after injury and treated at level-I trauma centers within the continental USA [6]. The ABOTrauma registry is based on Sweden and collects data on patients who had REBOA for the management of traumatic hemorrhagic shock from 25 institutions at 13 countries from Europe, Asia, and South America [7].

The AAST Multicenter Trials Committee and the Regional Ethics Committee of Uppsala, Sweden, approved the protocols for the AORTA and ABOTrauma registry, respectively. Also, all contributing hospitals received ethical approval from their own ethics committees.

\section{Patient groups}

Trauma patients undergoing REBOA were eligible for analysis. We planned to exclude patients undergoing REBOA for other indications different than trauma (i.e., non-traumatic hemorrhagic shock). Included patients were stratified depending on their classification in the World Bank Country and Lending groups [13]. In this classification, the World Bank divides the world's economies into four groups: high, upper-middle, lowermiddle, and low. However, due to the limited sample sub-group size, we decided to divide the patients into two groups: (1) high-income countries and (2) uppermiddle, lower-middle, and low-income countries.

The data merged from both registries was from 14 countries: 9 high-income countries (the USA, Israel, Sweden, Finland, Japan, Italy, South Korea, Germany, and the Netherlands), four upper-middle-income countries (Russia, Thailand, Colombia, and Turkey), and one low-income country (North Korea).

\section{Variables and outcomes}

Collected variables included demographic information, mechanism of injury, blood transfusion requirements, admission physiology, surgical interventions for bleeding control, REBOA access and deployment techniques, zone of the occlusion, organ failure, and mortality. Our primary endpoint was in-hospital mortality.

\section{Statistical analysis}

After merging the data from both registries, patients were classified according to the World Bank Country and Lending group of their country of origin: low to middle (LMICs) vs. high-income countries (HICs). Data 
were first compared between LMICs and HICs groups. Results were presented using frequencies and percentages for dichotomous and categorical variables and medians and inter-quartile ranges for continuous variables. Statistical comparisons between the two groups were made using Wilcoxon rank-sum test for continuous variables and chi-square tests or Fisher's exact tests in cell counts less than five for categorical variables.

Because REBOA resuscitated patients were not randomly assigned either to an LMIC or a HIC, a formal causal inference regarding the income of countries and the outcomes of interest is not possible. Therefore, to examine the contribution of the patient country of origin income, we generated a propensity score for each patient. For the propensity score, a logistic regression model was fit in order to predict each patient probability (propensity) of being from a LMIC or a HIC as a function of available covariates. These covariates were age, gender, the presence of pupillary response on admission, impending hypotension ( $\mathrm{SBP} \leq 80)$, trauma mechanism, ISS, the necessity of CPR on arrival, the location of REBOA insertion (emergency room or operating room), and the amount of PRBCs transfused in the first $24 \mathrm{~h}$.

Propensity score matching extracted 1:1 matched pairs of subjects who were from an LMICs or a HIC. Within the cohort of matched individuals, logistic regression was used to examine the association of LMICs and mortality. Logistic regression was adjusted by tachycardia $(H R \geq 100)$, procedure (laparotomy or pelvic surgery), the value of systolic blood pressure at REBOA initiation, and the need for massive transfusion ( $\geq 10$ PRBCs in the first $24 \mathrm{~h}$ ). All analyses were performed in the Stata 14 Statistical Software.

\section{Results}

A total of 817 trauma patients from 14 countries were treated with REBOA and included in the analysis.

Table 1 presents an overview of baseline characteristics and therapeutic strategies stratified by high and lowto-middle income countries, and the number of missing values for each variable. The median (IQR) of age was 42 (27-58.5); 204/817 (25\%) were female. Blunt trauma was the most common trauma mechanism (633/800; $79.1 \%$ ), and patients were often victims of severe injuries (ISS, median [IQR]: 34 [25-45]). Although there were no differences in severity scores between HICs and LMICs, patients from LMICs were less likely to receive prehospital and admission CPR. Also, a significantly higher proportion of them arrived with a systolic blood pressure of $80 \mathrm{mmHg}$ or less, and with tachycardia (Table 1). Patients from HICs received significantly higher amounts of red blood cells and plasma and were more likely to undergo angioembolization for hemorrhage control (Table 1).
Table 2 presents REBOA procedure-related information and outcomes. REBOA practice patterns were significantly different between the groups. Patients from HICs got their REBOA inserted more often in the emergency room $(n=520 / 710,73.2 \%)$; in contrast, a higher proportion of patients from LMICs underwent REBOA insertion in the operating room $(n=44 / 73,60.2 \%)(p<$ 0.001 ). While femoral artery cannulation by a blind percutaneous approach was the preferred access technique in HICs $(n=370 / 721,51.3 \%)$, surgical cutdown was more common in LIMCs $(n=43 / 73,58.9 \%)$. Access guided by ultrasound was performed in $30.6 \%$ and $21.9 \%$ of patients from HICs and LMICs, respectively. Overall, the majority of the REBOAs were deployed by a trauma surgeon $(547 / 727,75.2 \%)$. However, the participation of radiologists and anesthesiologists in the insertion and deployment was more frequent in HICs.

Patients from LMICs had a significantly higher occurrence of MODS $(\mathrm{LMICs}=45 / 68,66.1 \%$ vs. $\mathrm{HICs}=85 /$ $661,12.8 \% ; p<0,001)$, and respiratory failure (LMICs = $22 / 70,31.2 \%$ vs. HICs $=73 / 657,11.1 \%$; $p<0,001)$. There were no differences in the occurrence of acute kidney injury, sepsis, and groin access complications. Similarly, there were no differences in ventilator days and mortality between groups.

Table 3 presents the general characteristics, hemodynamics parameters, surgical and resuscitation strategies, REBOA procedure-related information, and outcomes for the propensity-matched cohort.

After the 1:1 propensity matching, LMICs $(n=66)$ and HICs $(n=66)$ groups were adequately balanced in the majority of their baseline characteristics. However, there were still significant differences in the rate of IR angioembolization $(\mathrm{LMICs}=2 / 66,3 \%$ vs. $\mathrm{HICs}=12 / 56$, $21.4 \% ; p=0.001$ ), the backgrounds of providers deploying REBOA, and the preferred access technique. Blind percutaneous approach and surgical cutdown were the preferred means of femoral cannulation in HICs (55.3\%) and LIMCs (57.5\%), respectively. Also, patients from LMICs had significantly lower values of SBP at REBOA initiation (SBP at REBOA initiation, median [IQR]: $\mathrm{LMIC}=50 \mathrm{mmHg}$ [32-65] vs. $\mathrm{HIC}=63 \mathrm{mmHg}$ [50-80]; $p<0.001)$.

The differences in the occurrence of MODS and respiratory failure persisted after the 1:1 propensity matching. A significantly higher proportion of patients from LIMCs presented these outcomes compared to patients from HICs. There were no differences in the occurrence of sepsis, acute kidney injury, and mortality between the propensity score-matched groups.

After adjusting by tachycardia ( $\mathrm{HR} \geq 100)$, procedure (laparotomy or pelvic surgery), the value of systolic blood pressure at REBOA initiation, and the need for massive transfusion ( $\geq 10 \mathrm{PRBCs}$ in the first $24 \mathrm{~h}$ ), 
Table 1 Baseline characteristics, resuscitation strategies, and surgical interventions between LMICs and HICs

\begin{tabular}{|c|c|c|c|c|c|}
\hline Variable & All $(n=817)$ & LMIC $(n=73)$ & HIC $(n=744)$ & $p$ value & Missing \\
\hline Age, median (IQR) & $42(27-58.5)$ & $37(27-49)$ & $43.5(27.5-59.5)$ & 0.08 & 13 \\
\hline Gender [female], $n$ (\%) & 204 (25\%) & $19(26 \%)$ & 185 (24.9\%) & 0.8 & 0 \\
\hline Trauma mechanism & & & & $<0.001$ & 17 \\
\hline Blunt, $n(\%)$ & 633/800 (79.1\%) & 42/73 (57.5\%) & $591 / 727(81.2 \%)$ & & \\
\hline Penetrating, $n(\%)$ & 167/800 (20.8\%) & $31 / 73(42.7 \%)$ & 136/727 (18.7\%) & & \\
\hline ISS, median (IQR) & $34(25-45)$ & $32(25-50)$ & $34(25-45)$ & 0.6 & 96 \\
\hline Pre-Hosp CPR, n (\%) & 165/786 (21\%) & $1 / 71(1.4 \%)$ & 164/715 (22.9) & $<0.001$ & 31 \\
\hline CPR on arrival, $n(\%)$ & 137/789 (17.3) & $3 / 73(4.1 \%)$ & 134/18.7 (18.7\%) & $<0.001$ & 28 \\
\hline Admission SBP & & & & $<0.001$ & 30 \\
\hline Not measurable & 149/787 (18.9\%) & 11/73 (15\%) & 138/714 (19.3\%) & & \\
\hline$<50$ & 58/787 (7.3\%) & 10/73 (13.7\%) & 48/714 (6.7\%) & & \\
\hline $50-80$ & 220/787 (27.9\%) & $41 / 73(56.1 \%)$ & 179/714 (56.1\%) & & \\
\hline 80-100 & $342 / 787$ (43.4\%) & 8/73 (10.9\%) & $334 / 714$ (46.7\%) & & \\
\hline$>100$ & 18/787 (2.2\%) & $3 / 73(4.1 \%)$ & 15/714 (2.1\%) & & \\
\hline Admission HR & & & & 0.005 & 55 \\
\hline$<50$ & $94 / 762(12.3 \%)$ & 6/72 (8.3\%) & $88 / 690$ (12.7\%) & & \\
\hline $50-100$ & $202(26.5 \%)$ & 15/72 (20.8\%) & 187/690 (27.1\%) & & \\
\hline 100-120 & 154/762 (20.2\%) & 26/72 (36.1\%) & 128/690 (18.5\%) & & \\
\hline$>120$ & $312 / 762(40.9 \%)$ & 25/72 (34.7\%) & 287/690 (41.6\%) & & \\
\hline Arrhythmia on admission, $n$ (\%) & 208/755 (27.8\%) & 10/72 (13.9\%) & 198/683 (29\%) & 0.006 & 62 \\
\hline Pupilary response, $n$ (\%) & $447 / 756(59.1 \%)$ & 63/73 (86.3\%) & $384 / 683(56.2 \%)$ & $<0.001$ & 61 \\
\hline Admission INR, median (IQR) & $1.4(1.2-1.7)$ & $1.4(1.2-1.6)$ & $1.4(1.2-1.8)$ & 0.9 & 355 \\
\hline Admission pH, median (IQR) & $7.16(7.01-7.26)$ & $7.19(7.03-7.28)$ & $7.16(7.01-7.26)$ & 0.5 & 229 \\
\hline Admission Lactate, median (IQR) & $7.2(4.3-11.3)$ & $5.9(4.4-11.02)$ & $7.2(4.3-11.3)$ & 0.5 & 255 \\
\hline PRBCs in first $24 \mathrm{~h}$, median (IQR) & $12(6-23)$ & $6(4-10)$ & $13(6.5-24)$ & $<0.001$ & 64 \\
\hline FFP in first $24 \mathrm{~h}$, median (IQR) & $10(4-20)$ & $5.5(3-9)$ & $10(4-20)$ & 0.001 & 83 \\
\hline Platelets in first $24 \mathrm{~h}$, median (IQR) & $3(1-10)$ & $6(0-10)$ & $3(1-10)$ & 0.7 & 116 \\
\hline Laparotomy, n (\%) & $476 / 774(61.5 \%)$ & $48 / 72(66.6 \%)$ & $428 / 702(61 \%)$ & 0.3 & 43 \\
\hline Pelvic Surgery, $n$ (\%) & 148/678 (21.8\%) & $9 / 73(12.3 \%)$ & 139/605 (22.9\%) & 0.03 & 139 \\
\hline Embolization, n (\%) & 105/707 (14.8\%) & 2/73 (2.7\%) & 103/634 (16.2\%) & 0.002 & 110 \\
\hline
\end{tabular}

logistic regression showed no differences in mortality for LMICs when compared to HICs; neither in the nonmatched cohort $(\mathrm{OR}=0.63 ; 95 \% \mathrm{CI} 0.36-1.09 ; p=0.1)$ nor in the matched cohort $(\mathrm{OR}=1.45 ; 95 \% \mathrm{CI} 0.63-3,33$; $p=0.3)$.

\section{Discussion}

This study, which reflects the worldwide practice patterns of REBOA for trauma patients by country income group, revealed considerable variation in the management practices of this intervention and the periinterventional surgical maneuvers used for its insertion and deployment between high and low-to-middle income countries. In addition to the variations in REBOA clinical practice patterns, we found significant differences in the clinical presentations, resuscitation strategies, surgical interventions, and some clinically relevant outcomes; however, with no differences in the risk-adjusted odds of mortality between the groups analyzed.

To our knowledge, this is the first study providing global insight into the use of REBOA as an adjunct for hemorrhage control and resuscitation in relation to the income of countries, and these results should encourage physicians using REBOA to step up efforts toward standardizing the practice of this endovascular strategy in order to treat patients similarly. Therefore, resulting in similar treatment patterns and surgical outcomes.

We found no differences in the risk-adjusted odds of mortality; however, patients from LMICs did have a significantly higher frequency of MODS and respiratory failure that persisted even after propensity score 
Table 2 REBOA use and outcomes between LMICs and HICs

\begin{tabular}{|c|c|c|c|c|c|}
\hline Variable & All $(n=817)$ & LMIC $(n=73)$ & HIC $(n=744)$ & $p$ value & Missing \\
\hline \multicolumn{6}{|l|}{ REBOA procedure } \\
\hline Access location & & & & $<0.001$ & 34 \\
\hline $\mathrm{ER}, n(\%)$ & $548 / 783$ (70\%) & 28/73 (38.3\%) & $520 / 710(73.2 \%)$ & & \\
\hline OR, $n(\%)$ & 214/783 (27.3\%) & $44 / 73(60.2 \%)$ & 170/710 (24.9\%) & & \\
\hline Angio, $n(\%)$ & 21/783 (2.6\%) & 1/73 (1.3\%) & 20/710 (2.8\%) & & \\
\hline Access technique & & & & $<0.001$ & 23 \\
\hline Blind, $n(\%)$ & $383 / 794$ (48\%) & 13/73 (17.8\%) & $370 / 721$ (51.3\%) & & \\
\hline US guided, $n$ (\%) & 237/794 (29.8\%) & 16/73 (21.9\%) & $221 / 721$ (30.6\%) & & \\
\hline Cut down, n (\%) & 162/794 (20.4\%) & 43/73 (58.9\%) & 119/721 (16.5\%) & & \\
\hline Fluoroscopy, n (\%) & $12 / 794(1.5 \%)$ & $1 / 73(1.37)$ & $11 / 721(1.53 \%)$ & & \\
\hline Cath/sheath diameter & & & & & 454 \\
\hline Primary performer & & & & $<0.001$ & 90 \\
\hline Vascular surgeon, $n(\%)$ & $53 / 727(7.2 \%)$ & 17/70 (24.2\%) & $36 / 657$ (5.1\%) & & \\
\hline Radiologist, $n$ (\%) & 26/727 (3.5\%) & $1 / 70(1.4 \%)$ & 25/657 (3.8\%) & & \\
\hline ER physician, $n$ (\%) & 70/727 (9.6\%) & 6/70 (8.5\%) & 64/657 (9.7\%) & & \\
\hline Trauma surgeon, $n(\%)$ & $547 / 727$ (75.2\%) & 43/70 (61.4\%) & 504/657 (76.7\%) & & \\
\hline General surgeon, $n(\%)$ & 7/727 (0.9\%) & $3 / 70(4.2 \%)$ & 4/657 (0.6\%) & & \\
\hline Anesthesiologist, $n$ (\%) & 13/727 (13\%) & 0/70 (0\%) & 13/657 (1.9\%) & & \\
\hline Resident/fellow, n (\%) & 11/727 (1.5\%) & 0/70 (0\%) & 11/657 (1.6\%) & & \\
\hline $\mathrm{SBP}$ at REBOA initiation, median (IQR) & $60(40-80)$ & $50(32-60)$ & $62(40-80)$ & $<0.001$ & 76 \\
\hline Zone of occlusion & & & & 0.02 & 10 \\
\hline Zone I, n (\%) & $555 / 807(68 \%)$ & $59 / 73(80.8 \%)$ & 496/734 (67.5\%) & & \\
\hline Zone II, n (\%) & 16/807 (1.9\%) & $2 / 73(2.7 \%)$ & 14/734 (1.9\%) & & \\
\hline Zone III, n (\%) & 236//807 & 12/73 (16.4\%) & $224 / / 734(30.5 \%)$ & & \\
\hline Confirmed balloon migration, $n(\%)$ & $39 / 817(4.7 \%)$ & $1 / 73(1.3 \%)$ & $38 / 681(5.1 \%)$ & 0.2 & 0 \\
\hline Groin access complications, n (\%) & 65/775 (8.3\%) & $6 / 70(8.5 \%)$ & $59 / 705(8.3 \%)$ & 0.9 & 42 \\
\hline$A K I, n(\%)$ & 137/743 (18.4\%) & $8 / 73(10.9 \%)$ & $129 / 670(19.5 \%)$ & 0.08 & 74 \\
\hline MODS, $n(\%)$ & 130/729 (17.8\%) & 45/68 (66.1\%) & $85 / 661(12.8 \%)$ & $<0.001$ & 88 \\
\hline Respiratory failure, $n$ (\%) & 95/727 (13.1\%) & $22 / 70(31.2 \%)$ & 73/657 (11.1\%) & $<0.001$ & 90 \\
\hline Sepsis, $n(\%)$ & $82 / 729(11.2 \%)$ & 9/70 (12.8\%) & 73/659 (11.1\%) & 0.6 & 88 \\
\hline Ventilator days, median (IQR) & $2(1-7)$ & $3(1-6)$ & $2(1-6)$ & 0.4 & 89 \\
\hline Mortality, n (\%) & $479(58.6 \%)$ & 37 (50.6\%) & $442(59.4 \%)$ & 0.1 & 0 \\
\hline
\end{tabular}

matching. Although previous studies have shown that REBOA can have a significant effect on the outcomes mentioned above [1, 14], the differences in pre-hospital medical services between LMICs and HICs offer a more plausible explanation for the results observed. The fact that patients from LMICs had worse outcomes in terms of organ failure may be due, in part, to the pervasive deficiencies in LMICs pre-hospital trauma care $[15,16]$, which is often limited by inadequate flow of transportation and lack of protocols for field triage and standards of pre-hospital care. Indeed, patients from LMICs included in this study were less likely to receive pre- hospital and admission CPR. The latter situations could be translated into an inadequate pre-hospital resuscitation of trauma patients, which may result in a poor physiological status on admission and, thereby, a higher chance of organ failure during the hospital stay.

On the other hand, although our finding on mortality is not surprising, it should be interpreted cautiously. The same deficiencies in LMICs pre-hospital care could have introduced significant survivorship bias, meaning that in LMICs, the patients with a higher chance of survival arrived in the emergency department and had the opportunity to get a REBOA. Improving pre-hospital care 
Table 3 General characteristics, hemodynamics parameters, surgical and resuscitation strategies, REBOA procedure-related information, and outcomes for the propensity-matched cohort

\begin{tabular}{|c|c|c|c|c|c|}
\hline Variable & All $(n=132)$ & LMIC $(n=66)$ & HIC $(n=66)$ & $p$ value & Missing \\
\hline Age, median (IQR) & $35.5(25-51.5)$ & $36(27-49)$ & $34.5(24-57)$ & 0.5 & 0 \\
\hline Gender [female], $n(\%)$ & $32(24.2 \%)$ & $17(25.7 \%)$ & 15 (22.7\%) & 0.6 & 0 \\
\hline Trauma mechanism & & & & 0.1 & 0 \\
\hline Blunt, $n(\%)$ & $82(62.1 \%)$ & 37 (56\%) & $45(68.1 \%)$ & & \\
\hline Penetrating, $n(\%)$ & $50(37.9 \%)$ & $29(44 \%)$ & $21(31.9 \%)$ & & \\
\hline ISS, median (IQR) & $32(25-48)$ & $32(25-48)$ & $32.5(25-45)$ & 0.7 & \\
\hline Pre-hosp CPR, $n(\%)$ & $4 / 129(3.1 \%)$ & $1 / 64(1.5 \%)$ & $3 / 65(4.6)$ & 0.6 & 3 \\
\hline CPR on arrival, $n(\%)$ & $3(2.3 \%)$ & $1(1.5 \%)$ & $2(3 \%)$ & 1 & 0 \\
\hline Admission SBP & & & & 0.1 & 0 \\
\hline Not measurable & $16(12.1 \%)$ & $9(13.6 \%)$ & $7(10.6 \%)$ & & \\
\hline$<50$ & $16(12.1 \%)$ & $9(13.6 \%)$ & $7(10.6 \%)$ & & \\
\hline $50-80$ & $80(60.6 \%)$ & 39 (59.1\%) & $41(62.1 \%)$ & & \\
\hline 80-100 & $9(6.8 \%)$ & $7(10.6 \%)$ & $2(3 \%)$ & & \\
\hline$>100$ & $11(8.3 \%)$ & $2(3 \%)$ & $9(13.6 \%)$ & & \\
\hline Admission HR & & & & 0.01 & 3 \\
\hline$<50$ & 5/129 (3.8\%) & 4/65 (6.15\%) & $1 / 64(1.5 \%)$ & & \\
\hline 50-100 & 24/129 (18.6\%) & 12/65 (18.4\%) & 12/64 (18.7\%) & & \\
\hline 100-120 & $37 / 129$ (28.6\%) & 25/65 (38.4\%) & 12/64 (18.7\%) & & \\
\hline$>120$ & 63/129 (48.8\%) & 24/65 (36.9\%) & 39/64 (60.9\%) & & \\
\hline Admission $\mathrm{HR} \geq 100, n(\%)$ & 100/129 (77.5\%) & 49/65 (75.3\%) & $51 / 64(79.6 \%)$ & 0.5 & 3 \\
\hline Arrhythmia on admission, $n$ (\%) & 18/115 (15.6\%) & $7 / 66(10.6 \%)$ & $22 / 49(22.4 \%)$ & 0.08 & 17 \\
\hline Pupilary response, $n$ (\%) & $115(87.1 \%)$ & $59(89.3 \%)$ & $56(84.8 \%)$ & 0.4 & 0 \\
\hline Admission INR, median (IQR) & $1.36(1.2-1.6)$ & $1.37(1.23-1.62)$ & $1.35(1.2-1.6)$ & 0.3 & 53 \\
\hline Admission pH, median (IQR) & $7.19(7.03-7.28)$ & $7.21(7.03-7.28)$ & $7.19(7-7.27)$ & 0.9 & 22 \\
\hline Admission lactate, median (IQR) & $6.8(4-10.8)$ & $5.8(4.3-10.8)$ & $7.2(4-10.4)$ & 0.4 & 33 \\
\hline PRBCs in first $24 \mathrm{~h}$, median (IQR) & $7(4-10)$ & $6(4-10)$ & $8(4-12)$ & 0.3 & 0 \\
\hline FFP in first $24 \mathrm{~h}$, median (IQR) & $5(2-10)$ & $6(3-9)$ & $5(2-10)$ & 0.4 & 4 \\
\hline Platelets in first $24 \mathrm{~h}$, median (IQR) & $2(0-6)$ & $6(0-10)$ & $2(0-4)$ & 0.1 & 17 \\
\hline Laparotomy, n (\%) & $88 / 130(67.7 \%)$ & $45 / 65(69.2 \%)$ & 43/65 (66.1\%) & 0.7 & 2 \\
\hline Pelvic surgery, $n(\%)$ & 22/121 (18.2\%) & 9/66 (13.6\%) & 13/55 (23.6\%) & 0.1 & 11 \\
\hline Embolization, n (\%) & 14/122 (11.4\%) & $2 / 66$ (3\%) & $12 / 56(21.4 \%)$ & 0.001 & 10 \\
\hline \multicolumn{6}{|l|}{ REBOA procedure } \\
\hline Access location & & & & 0.09 & \\
\hline $\mathrm{ER}, n(\%)$ & $59(44.7 \%)$ & $24(36.3 \%)$ & 35 (53\%) & & \\
\hline OR, n (\%) & 71 (53.8\%) & $41(62.1 \%)$ & $30(45.4 \%)$ & & \\
\hline Angio, $n$ (\%) & $2(1.5 \%)$ & $1(1.5 \%)$ & $1(1.5 \%)$ & & \\
\hline Access technique & & & & $<0.001$ & 1 \\
\hline Blind, $n(\%)$ & 48/131 (36.6\%) & 12/66 (18.1\%) & $36 / 65$ (55.3\%) & & \\
\hline US guided, $n$ (\%) & $38 / 131$ (29\%) & 15/66 (22.7\%) & 23/65 (35.4\%) & & \\
\hline Cut down, n (\%) & 43/131 (32.8\%) & 38/66 (57.5\%) & $5 / 65(7.6 \%)$ & & \\
\hline Fluoroscopy, n (\%) & 2/131 (1.5\%) & $1 / 66(1.5 \%)$ & $1 / 65(1.5 \%)$ & & \\
\hline Primary performer & & & & 0.001 & 11 \\
\hline Vascular surgeon, n (\%) & 18/121 (14.9\%) & 14/64 (21.8\%) & 4/57 (7\%) & & \\
\hline
\end{tabular}


Table 3 General characteristics, hemodynamics parameters, surgical and resuscitation strategies, REBOA procedure-related information, and outcomes for the propensity-matched cohort (Continued)

\begin{tabular}{|c|c|c|c|c|c|}
\hline Variable & All $(n=132)$ & LMIC $(n=66)$ & HIC $(n=66)$ & $p$ value & Missing \\
\hline Radiologist, $n$ (\%) & $7 / 121(5.8 \%)$ & $1 / 64(1.5 \%)$ & $6 / 57(10.5 \%)$ & & \\
\hline ER physician, $n(\%)$ & $7 / 121(5.8 \%)$ & $6 / 64(9.3 \%)$ & $1 / 57(1.7 \%)$ & & \\
\hline Trauma surgeon, $n(\%)$ & $82 / 121(67.7 \%)$ & $40 / 64(62.5 \%)$ & $42 / 57(73.6 \%)$ & & \\
\hline General surgeon, $n(\%)$ & $3 / 121(2.4 \%)$ & $3 / 64(4.6 \%)$ & $0 / 57(0 \%)$ & & \\
\hline Anesthesiologist, $n(\%)$ & $3 / 121(2.5 \%)$ & 0/64 (0\%) & $3 / 57(5.2 \%)$ & & \\
\hline Resident/fellow, $n$ (\%) & $1(2.5 \%)$ & 0/64 (0\%) & $1 / 57(1.7 \%)$ & & \\
\hline SBP at REBOA initiation, median (IQR) & $60(40-70)$ & $50(32-65)$ & $63(50-80)$ & $<0.001$ & 6 \\
\hline Zone of occlusion & & & & 0.1 & 0 \\
\hline Zone I, n (\%) & $98(74.2 \%)$ & $53(80.3 \%)$ & $45(68.1 \%)$ & & \\
\hline Zone II, n (\%) & $3(2.2 \%)$ & $2(3 \%)$ & $1(1.5 \%)$ & & \\
\hline Zone III, n (\%) & $31(23.4 \%)$ & $11(16.7 \%)$ & $20(30.3 \%)$ & & \\
\hline Confirmed balloon migration, $n(\%)$ & $2(1.5 \%)$ & $1(1.5 \%)$ & $1(1.5 \%)$ & 1 & 0 \\
\hline Groin access complications, $n$ (\%) & $16 / 125(12.8 \%)$ & $6 / 64(9.3 \%)$ & $10 / 61(16.3 \%)$ & 0.2 & 7 \\
\hline AKI, $n(\%)$ & $21 / 129(16.2 \%)$ & $8 / 66(12.1 \%)$ & 13/63 (20.6\%) & 0.1 & 3 \\
\hline MODS, n (\%) & $54 / 124(43.4 \%)$ & 43/62 (69.3\%) & $11 / 62(17.7 \%)$ & $<0.001$ & 8 \\
\hline Respiratory failure, $n$ (\%) & $33 / 125$ (26.4\%) & $22 / 64(34.4 \%)$ & 11/61 (18\%) & 0.03 & 7 \\
\hline Sepsis, $n(\%)$ & 15/125 (12\%) & $9 / 64(14 \%)$ & $6 / 61(9.8 \%)$ & 0.4 & 7 \\
\hline Ventilator days, median (IQR) & $3(1-9)$ & $3,5(1-9)$ & $3(1-9)$ & 0.6 & 5 \\
\hline Mortality, n (\%) & $57(43.1 \%)$ & $31(49.9 \%)$ & $26(39.4 \%)$ & 0.3 & 0 \\
\hline
\end{tabular}

in LIMCs while simultaneously implementing endovascular trauma management should be a priority for trauma stakeholders to further the field of trauma care globally.

What is surprising is that the hospital scenario for REBOA insertion and techniques for femoral artery cannulation varied widely between the groups analyzed. While in LMICs, the insertion and deployment of REBOA occurred more frequently in the operating room and by surgical cutdown, in HICs, these procedures were performed more often in the emergency room and by blind percutaneous insertion. Previous studies have shown a higher incidence of groin access complications when REBOA is inserted by surgical cutdown [17], and some authors recommend in favor of performing groin access in an operating room controlled setting [18]. Therefore, our findings are of concern because a lack of standardization of surgical procedures for REBOA insertion and deployment can jeopardize clinical outcomes and patient safety. We urge a shift in REBOA surgical practice toward ultrasound-guided access, with surgeons adopting a more cautious, safe, and systematic approach to REBOA insertion and deployment. To this end, trauma surgeons using this endovascular technology should follow published guidelines and recommendations $[19,20]$; however, they should be prepared to adapt these guidelines to make them appropriate for their local trauma-system reality and develop simple, scalable solutions to improve the delivery of REBOA, regardless of the income of their country of origin.

This study revealed that different surgeons are using different approaches for similar indications and modified surgical procedures when using the same endovascular intervention. For example, we found a significant difference in the use of IR angioembolization as a method for bleeding control, with higher use of this modality in HICs. Also, ultrasound was more frequently used during REBOA insertion in high-income countries, and the proportion of radiologists involved in REBOA use was higher in these countries. It can be inferred that the higher the income, the greater the capacity of the healthcare system to allocate resources to offer more advanced care with better technology. Therefore, it is rational to posit that these clinical practice behaviors are plausibly related to the income of the regions where trauma surgeons are practicing.

It is now clear that there is variability in the REBOA clinical practice patterns in trauma care between LMICs and HICs. Nevertheless, these differences can provide meaningful opportunities to examine and include the perspectives from trauma surgeons practicing in LMICs 
into the teams producing the guidelines for REBOA use. To date, some guidelines have been published in well-recognized international journals [19-21]. Of note, however, these guidelines often lack the representation of physicians from LMICs in their list of authors, and only a few studies performed in LMICs are included in the references supporting the guidelines. These disparities raise concerns that the challenges and problems on trauma care and REBOA implementation inherent to LMICs could be inadequately addressed $[4,10]$. Moreover, the lack of inclusion of stakeholders from LMICs into REBOA clinical guidelines may be of greater concern because most of the world's population lives in LMICs, where the burden of traumatic injuries is enormous, and outcomes are often poor [22]. Therefore, future international REBOA guidelines should aim to be more globally applicable, with dedicated recommendations for its use in LMICs. In this way, the practice and delivery of REBOA could be optimized globally and enhanced most favorably for all.

To bridge the gap between HICs and LMICs, trauma surgeons practicing either in low-volume centers or in low resource settings should implement policies to improve endovascular trauma management quality. These quality improvement policies should include a complete REBOA curriculum, including educational goals and assessment of learning outcomes.

\section{Limitations}

Our study has its limitations, and results should be interpreted in the context of the datasets used and the analyses performed. First, our study was at risk of residual confounding because information on some clinically relevant variables was not collected. This lack of data granularity could affect risk adjustment, even after using propensity score matching. Second, the lack of uniformity of diagnostic and therapeutic approaches between the reporting centers may have affected the outcomes observed, further comprising the validity of our results and the interpretations derived from them. Third, because we did not perform sample size calculations, this study may not have adequate power to detect the true effect of the countries' income on REBOA-treated patients.

Despite our limitations, we believe that the countries' income can be used as a proxy for the health care services' capacity of each country. Therefore, the REBOA outcomes information related to this exposure should provide essential insights on how trauma-system and hospital capacity planning could be improved and adapted to the implementation of novel endovascular approaches for bleeding control.

\section{Conclusion}

There is considerable variation in the management practices of REBOA and the outcomes associated with this intervention between high and low-to-middle income countries. Trauma surgeons practicing REBOA around the world should joint efforts to standardize the practice of this endovascular technology worldwide.

\section{Abbreviations}

REBOA: Resuscitative endovascular balloon occlusion of the aorta

\section{Acknowledgements}

The authors want to thank the contributors at each participating center.

\section{Contributors}

AAST AORTA Investigators

Jonny Morrison, MD, PhD; Thomas M. Scalea, MD (University of Maryland/R Adams Cowley Shock Trauma Center, Baltimore, MD, USA). Laura J. Moore, MD, FACS; Jeanette M Podbielski, RN, CCRP; John B. Holcomb, MD (University of Texas Health Sciences Center-Houston Houston, TX, USA). Kenji Inaba, MD; Alice Piccinini, MD (Los Angeles County + University of Southern California Hospital, Los Angeles, CA, USA). David S. Kauvar, MD, FACS; Valorie L. Baggenstoss, MSN, RN; Catherine Rauschendorfer BSN, RN (San Antonio Military Medical Center/US Army Institute of Surgical Research, San Antonio, TX, USA). Jeremey Cannon, MD; Mark Seamon, MD; Ryan Dumas, MD; Mike Vella, Jessica Guzman (University of Pennsylvania, Philadelphia, PA, USA). Chance Spalding, DO, PhD; Timothy W. Wolff, DO (Ohio Health, Columbus, Ohio, USA). Chuck Fox, MD; Ernest Moore, MD (Denver Health and Hospital Authority, Denver, CO USA). David Turay, MD; Cassra N. Arbabi, MD; Xian Luo-Owen, PhD (Loma Linda University Medical Center, Loma Linda, CA, USA). David Skarupa, MD; Jennifer A. Mull, RN, CCRC; Joannis Baez Gonzalez (University of Florida - Jacksonville, Jacksonville, FL, USA). Joseph Ibrahim, MD; Karen Safcsak RN, BSN (Orlando Regional Medical Center, Orlando, FL, USA). Stephanie Gordy, MD; Michael Long, MD (Ben Taub General Hospital/ Baylor College of Medicine, Houston, TX, USA). Andrew W. Kirkpatrick, MD; Chad G. Ball, MD; Zhengwen Xiao, MD, MSc, PhD (Foothills Medical Centre, Calgary, Alberta, Canada). Elizabeth Dauer, MD (Temple University, Philadelphia, PA, USA). Jennifer Knight, MD; Nicole Cornell, BS, MS (West Virginia University Hospitals, Morgantown, WV, USA). Forrest "Dell" Moore, MD (John

Peter Smith Hospital, Fort Worth, TX, USA). Matthew Bloom, MD (Cedars Sinai Hospital, Los Angeles, CA, USA). Nam T. Tran, MD; Eileen Bulger, MD (University of Washington - Harborview, Seattle, WA, USA). Jeannette G. Ward, MSCR (Chandler Regional Medical Center, Chandler, AZ, USA). John K. Bini, MD; John Matsuura, MD; Joshua Pringle, MD;Karen Herzing, BSN, RN; Kailey Nolan, BS (Wright State Research Institute - Miami Valley Hospital, Dayton, OH, USA). Nathaniel Poulin, MD (Vidant Medial Center, Greeneville, NC, USA). William Teeter, MD (University of North Carolina at Chapel Hill, Chapel Hill, NC, USA). Rachel Nygaard, PhD; Chad Richardson, MD; Joseph Skaja, MD; Derek Lombard, MD (Hennepin Healthcare, Minneapolis, MN, USA). Reagan Bollig, MD; Brian Daley, MD; Niki Rasnake, BSN, RN, CEN (University of Tennessee Medical Center, Knoxville, TN, USA). Marko Bukur, MD; Elizabeth Warnack, MD (Bellevue Hospital/NYU, New York, NY, USA). Joseph Farhat, MD (North Memorial Medical Center, Minneapolis, MN, USA). Robert M. Madayag, MD, FACS; Pamela Bourg, PhD, RN, TCRN, FAEN (St. Anthony Hospital, Lakewood, CO, USA). ABOTrauma Registry Group

Anna Ramstedt; Mitra Sadeghi; Kristofer F. Nilsson; Thomas Larzon; Artai Pirouzram; Asko Toivola (Department of Cardiothoracic and Vascular Surgery, Faculty of Medicine and Health, Örebro University, Örebro, Sweden). Mariusz Maszkowski; Adam Bersztel (Västmanlands Hospital Västerås, Department of Vascular Surgery, Örebro University, Örebro, Sweden). Per Skoog (Department of Hybrid and Interventional Surgery, Unit of Vascular Surgery, Sahlgrenska University Hospital, Gothenburg, Sweden). Koji Idoguchi (Senshu Trauma and Critical Care Center, Rinku General Medical Center, Izumisano, Japan). Yuri Kon (Emergency and Critical Care Center, Hachinohe City Hospital,

Hachinohe, Japan). Tokiya Ishida (Emergency and Critical Care Center, Ohta Nishinouchi Hospital, Koriyama, Japan). Yosuke Matsumura (Department of Emergency and Critical Care Medicine, Chiba University Graduate School of Medicine, Chiba, Japan). Junichi Matsumoto (Department of Emergency and Critical Care Medicine, St Marianna University School of Medicine, Kawasaki, 
Japan). Viktor Reva (Department of War Surgery, Kirov Military Medical Academy, Saint Petersburg, Russia). Eva-Corina Caragounis (Sahlgrenska University Hospital, Department of Surgery, University of Gothenburg, Gothenburg, Sweden). Mårten Falkenberg (Department of Radiology, Sahlgrenska University Hospital, Gothenburg, Sweden). Lauri Handolin (Helsinki University Hospital, Department of Orthopedics and Traumatology, University of Helsinki, Helsinki, Finland). George Oosthuizen; Endre Szarka; Vassil Manchev (Pietermaritzburg Metropolitan Trauma Service, Department of Surgery, University of KwaZulu-Natal College of Health Sciences, Pietermaritzburg, KwaZulu-Natal, South Africa). Tongporn Wannatoop (Department of Surgery. Faculty of Medicine Siriraj Hospital, Mahidol University, Bangkok, Thailand). Sung W. Chang (Department of Thoracic and Cardiovascular Surgery, Trauma Center, Dankook University Hospital, Cheonan, Republic of Korea). Boris Kessel; Dan Hebron (Department of Surgery, Hillel Yaffe Medical Centre, Hadera, Israel). Gad Shaked (Department of Anesthesiology and Critical Care, Soroka University Medical Center, Ben Gurion University, Beer Sheva, Israel). Miklosh Bala (Trauma and Acute Care Surgery Unit, Hadassah Hebrew University Medical Center, Jerusalem, Israel). Federico Coccolini; Luca Ansaloni (Department of General Emergency and Trauma Surgery, Bufalini Hospital, Cesena, Italy). Peter Hibert-Carius (Department of Anesthesiology, Emergency and Intensive Care Medicine, Bergmannstrost Hospital Halle, Halle, Germany). Michelle Moe; Suzanne Maria Vrancken.

\section{Authors' contributions}

Only authors who made substantive intellectual contributions were listed as authors. All authors conceived the idea. Manzano-Nunez performed the statistical analysis. All authors provided writing assistance and performed critical revision of the manuscript for relevant intellectual content. All authors approved the final version for submission.

\section{Funding}

The authors received no financial support for the research, authorship, and/ or publication of this article.

\section{Availability of data and materials}

The datasets generated and/or analyzed during the current study are not publicly available but could be available from the corresponding author on reasonable request.

\section{Ethics approval and consent to participate}

Ethics approval was obtained from the IRB at each participating center. All procedures performed in studies involving human participants were in accordance with the ethical standards of the institutional research committee from each participating center and with the 1964 Helsinki Declaration and its later amendments or comparable ethical standards.

\section{Consent for publication}

Not applicable

\section{Competing interests}

The authors declare that they have no conflict of interest. The views expressed in this material are those of the authors and do not reflect the official policy of position of the US Government, the Department of Defense, the Department of the Air Force, or any of the affiliated institutions.

\section{Author details}

${ }^{1}$ Clinical Research Center, Fundacion Valle del Lili, Cali, Colombia.

2Universidad del Rosario, Escuela de Medicina y Ciencias de la Salud, Bogotá, Colombia. ${ }^{3}$ Méderi Hospital Universitario Mayor, Carrera 24 No 63 C - 69 Barrio Siete de Agosto, Bogotá, DC, Colombia. ${ }^{4}$ R. Adams Cowley Shock Trauma, Baltimore, MD, USA. ${ }^{5}$ Department of Surgery, Fundación Valle del Lili, Cali, Colombia. ${ }^{6}$ Department of Cardiothoracic and Vascular Surgery, Faculty of Medicine and Health, Örebro University, Örebro, Sweden.

\section{Received: 30 July 2020 Accepted: 27 September 2020}

Published online: 12 October 2020

\section{References}

1. Manzano Nunez R, Naranjo MP, Foianini E, Ferrada P, Rincon E, GarcíaPerdomo $\mathrm{HA}$, et al. A meta-analysis of resuscitative endovascular balloon occlusion of the aorta (REBOA) or open aortic cross-clamping by resuscitative thoracotomy in non-compressible torso hemorrhage patients. World J Emerg Surg. 2017;12:30.

2. Hörer T. Resuscitative endovascular balloon occlusion of the aorta (REBOA) and endovascular resuscitation and trauma management (EVTM): a paradigm shift regarding hemodynamic instability. Eur J Trauma Emerg Surg. 2018;44:487-9.

3. Brenner M, Teeter W, Hoehn M, Pasley J, Hu P, Yang S, et al. Use of resuscitative endovascular balloon occlusion of the aorta for proximal aortic control in patients with severe hemorrhage and arrest. JAMA Surg. 2017; 21201:1-6.

4. Ordoñez CA, Khan M, Cotton B, Perreira B, Brenner M, Ferrada P, et al. The Colombian experience in resuscitative endovascular balloon occlusion of the aorta (REBOA): the progression from a large caliber to a low-profile device at a level I trauma center. Shock. Online ahead of print. doi: 10.1097/ SHK.0000000000001515. Accessed March 25, 2020.

5. Aso S, Matsui H, Fushimi K, Yasunaga H. Resuscitative endovascular balloon occlusion of the aorta or resuscitative thoracotomy with aortic clamping for noncompressible torso hemorrhage: a retrospective nationwide study. J Trauma Acute Care Surg. 2017:82:910-4.

6. Joseph JD, Thomas MS, Megan B, Dimitra S, Kenji I, Jeremy C, et al. The AAST prospective aortic occlusion for resuscitation in trauma and acute care surgery (AORTA) registry: data on contemporary utilization and outcomes of aortic occlusion and resuscitative balloon occlusion of the aorta (REBOA). J Trauma Acute Care Surg. 2016;81:409-19.

7. Sadeghi M, Nilsson KF, Larzon T, Pirouzram A, Toivola A, Skoog P, et al. The use of aortic balloon occlusion in traumatic shock: first report from the $A B O$ trauma registry. Eur J Trauma Emerg Surg. 2018;44:491-501.

8. Joseph B, Zeeshan M, Sakran JV, Hamidi M, Kulvatunyou N, Khan M, et al. Nationwide analysis of resuscitative endovascular balloon occlusion of the aorta in civilian trauma. JAMA Surg. 2019;154:500-8.

9. Abe T, Uchida M, Nagata I, Saitoh D, Tamiya N. Resuscitative endovascular balloon occlusion of the aorta versus aortic cross clamping among patients with critical trauma: a nationwide cohort study in Japan. Crit Care. 2016;20:400.

10. García AF, Manzano-Nunez R, Orlas CP, Ruiz-Yucuma J, Londoño A, Salazar $C$, et al. Association of resuscitative endovascular balloon occlusion of the aorta (REBOA) and mortality in penetrating trauma patients. Eur J Trauma Emerg Surg. Online ahead of print. doi: 10.1007/s00068-020-01370-9. Accessed March 25, 2020

11. Brenner M, Inaba K, Aiolfi A, DuBose J, Fabian T, Bee T, et al. Resuscitative endovascular balloon occlusion of the aorta and resuscitative thoracotomy in select patients with hemorrhagic shock: early results from the American Association for the Surgery of Trauma's aortic occlusion in resuscitation for trauma and Acu. J Am Coll Surg Elsevier. 2018;226:730-40.

12. Coccolini F, Ceresoli M, McGreevy DT, Sadeghi M, Pirouzram A, Toivola A, et al. Aortic balloon occlusion (REBOA) in pelvic ring injuries: preliminary results of the $\mathrm{ABO}$ trauma registry. Updat Surg. 2020

13. World Bank Country and Lending Groups. (2020). Available from: https:// datahelpdesk.worldbank.org/knowledgebase/articles/906519-world-bankcountry-and-lending-groups. Accessed 22 Feb 2020.

14. Morrison JJ, Galgon RE, Jansen JO, Cannon JW, Rasmussen TE, Eliason JL, et al. A systematic review of the use of resuscitative endovascular balloon occlusion of the aorta in the management of hemorrhagic shock. J Trauma Acute Care Surg. 2016;80:324-34.

15. Nielsen K, Mock C, Joshipura M, Rubiano AM, Zakariah A, Rivara F. Assessment of the status of prehospital care in 13 low- and middle-income countries. Prehosp Emerg Care. 2012/04/10. 2012;16:381-9.

16. Suryanto undefined, Plummer $\mathrm{V}$, Boyle M. EMS systems in lower-middle income countries: a literature review. Prehosp Disaster Med. 2016/12/12. Cambridge University Press; 2017;32:64-70.

17. Manzano-Nunez R, Orlas CP, Herrera-Escobar JP, Galvagno S, DuBose J, Melendez JJ, et al. A meta-analysis of the incidence of complications associated with groin access after the use of resuscitative endovascular balloon occlusion of the aorta in trauma patients. J Trauma Acute Care Surg. 2018;85:626-34.

18. Bekdache O, Paradis T, Shen YBH, Elbahrawy A, Grushka J, Deckelbaum D, et al. Resuscitative endovascular balloon occlusion of the aorta (REBOA): indications: advantages and challenges of implementation in traumatic non-compressible torso hemorrhage. Trauma Surg Acute Care Open. 2019;4 e000262.

19. Brenner M, Bulger EM, Perina DG, Henry S, Kang CS, Rotondo MF, et al. Joint statement from the American College of Surgeons Committee on trauma 
(ACS COT) and the American College of Emergency Physicians (ACEP) regarding the clinical use of resuscitative endovascular balloon occlusion of the aorta (REBOA). Trauma Surg Acute Care Open. 2018;e000154:3.

20. Cannon J, Morrison J, Laurer C, Grabo D, Polk T, Blackbourne L, et al. Resuscitative endovascular balloon occlusion of the aorta (REBOA) for hemorrhagic shock. Mil Med. 2018;1:55-9.

21. Bulger EM, Perina DG, Qasim Z, Beldowicz B, Brenner M, Guyette F, et al. Clinical use of resuscitative endovascular balloon occlusion of the aorta (REBOA) in civilian trauma systems in the USA, 2019: a joint statement from the American College of Surgeons Committee on trauma, the American College of Emergency Physicians, the. N Trauma Surg Acute Care Open. 2019;e000376:4

22. Haagsma JA, Graetz N, Bolliger I, Naghavi M, Higashi H, Mullany EC, et al. The global burden of injury: incidence, mortality, disability-adjusted life years and time trends from the global burden of disease study 2013. Inj Prev. 2015;22:3-18.

\section{Publisher's Note}

Springer Nature remains neutral with regard to jurisdictional claims in published maps and institutional affiliations.

Ready to submit your research? Choose BMC and benefit from:

- fast, convenient online submission

- thorough peer review by experienced researchers in your field

- rapid publication on acceptance

- support for research data, including large and complex data types

- gold Open Access which fosters wider collaboration and increased citations

- maximum visibility for your research: over $100 \mathrm{M}$ website views per year

At $B M C$, research is always in progress.

Learn more biomedcentral.com/submissions 